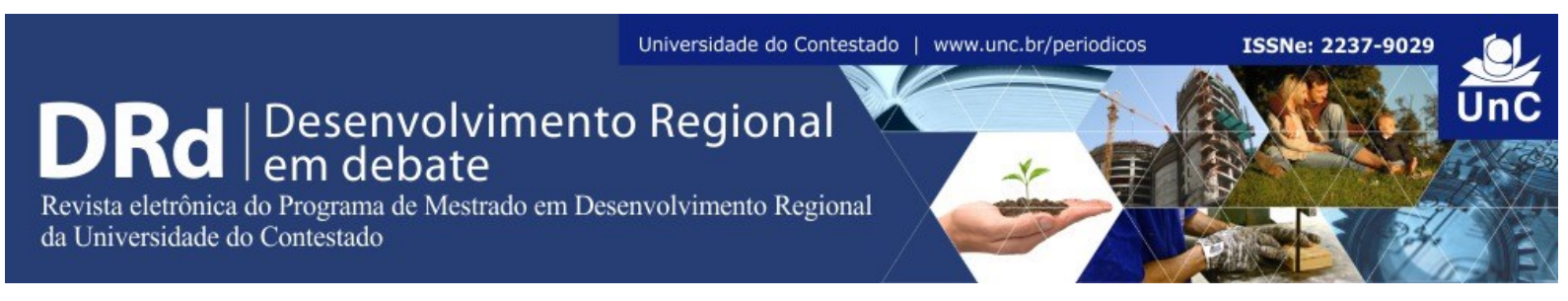

PACTOS SOCIOTERRITORIAIS PARA O VIVER BEM

Ener Vaneski Filho ${ }^{1}$

\title{
RESENHA DO LIVRO
}

DALLABRIDA, Valdir Roque. Teorias do Desenvolvimento: aproximações teóricas que tentam explicar as possibilidades e desafios quanto ao desenvolvimento de lugares, regiões, territórios ou países. Curitiba: CRV, 2107. 238 p.



O livro do Professor e Pesquisador Valdir Roque Dallabrida sintetiza de forma objetiva e didática em uma abordagem multidisciplinar o conjunto de teorias, enfoques ou abordagens teóricas que genericamente são chamadas de Teorias do Desenvolvimento, sempre com ênfase na dimensão espacial do processo histórico. A obra sistematiza desde reflexões sobre o sentido do desenvolvimento até a questão chave do livro: porque algumas regiões se desenvolvem e outras não, ou ainda, como identificar os diferentes níveis socioeconômicos e projetos de futuro de diferentes territórios, lugares, regiões ou países.

O autor destaca que o desenvolvimento difere de crescimento econômico e não é uma receita e nem um estágio a ser transposto, e sim um processo de mudança situado histórica e territorialmente. Como bem lembrado pelo autor, o livro se destina a um público amplo, não se restringindo ao universo acadêmico monodisciplinar. Utilizando-se de conceitos básicos de Economia, Geografia, Sociologia, Ciência Política e de temas comuns à preocupação de gestores, empresários, estudantes, educadores, lideranças locais e regionais, ativistas e todos os que buscam o verdadeiro desenvolvimento de um território específico, a leitura é útil àqueles que pretendem aprofundar seus conhecimentos sobre as teorias do desenvolvimento.

Utilizando mais de quatro centenas de referências, obras clássicas, contemporâneas, livros, capítulos, artigos e coletâneas dos principais autores, a obra apresenta um verdadeiro dicionário sobre desenvolvimento territorial, cujo conteúdo está comentado em notas de rodapé. Juntas somam praticamente 500 verbetes, indicações de leituras e explicações para os leitores que desejem aprofundar a análise instigante, crítica, histórica e escalar do desenvolvimento.

\footnotetext{
${ }^{1}$ Doutorando em Meio Ambiente e Desenvolvimento na Universidade Federal do Paraná (MADE/UFPR). Mestre em Desenvolvimento Territorial na América Latina e Caribe pela Universidade Estadual Paulista (UNESP). Graduado em Geografia pela Faculdade Estadual de Filosofia, Ciências e Letras de União da Vitória - PR (FAFIUV). Técnico em Reforma e Desenvolvimento Agrário, no Instituto Nacional de Colonização e Reforma Agrária (INCRA). Paraná. Brasil. E-mail: enervan@yahoo.com.br
} 
O livro está organizado em cinco capítulos. No primeiro encontra-se uma abordagem da teórica econômica clássica, de autores com enfoques espaciais ou de crescimento regional, como: Smith, Ricardo, Marx, Marshall, Shumpeter, Keynes, North, Rostow, Myrdal, Hirschman, Perroux, Solow, Romer e Lucas. Na sequência, encontram-se abordagens sobre a Ciência Regional e a contribuição de autores neomarxistas, como Samir Amin, Guder Frank, Paul Baran e Rui Mauro Marini.

Também é dado destaque para a importante diferenciação entre os autores da teoria da dependência. De um lado os "Weberianos" e a defesa do desenvolvimento industrializanteassociado, e de outro, os da corrente marxista que propunham um rompimento da periferia com o centro, com destaque para Rui Mauro Marini.

Resgatam-se, ainda, as ideias dos Fisiocratas Franceses, que viam o desenvolvimento como crescimento do excedente da produção agrícola até o enfoque da Ciência Regional: trata-se de um grande percorrido histórico, onde não se pode deixar de destacar o que o autor sinaliza: "[...] a questão do subdesenvolvimento/dependência aparece diagnosticada pela maioria dos autores, porém eles divergem quanto à direção da determinação" (p. 64).

O segundo capítulo, por sua vez, tem como foco a contribuição de teóricos Latinoamericanos. Nele é apresentado o chamado "Estruturalismo Latino-americano" com temas, tais como, Trocas Desiguais, distribuição dos meios de produção (Reforma Agrária); teoria do Centro-periferia e da Dependência; análise da Divisão Internacional do Trabalho entre 1880 e 1945, as quais mostram a deterioração das relações de troca em desfavor aos países da região (crescimento empobrecedor). Assim, há destaque para as contribuições de Raul Prebisch e Celso Furtado, autores que trabalharam na Comissão Econômica para América Latina (CEPAL), que podem sem considerados "desenvolvimentistas". Ainda são lembrados os autores da corrente Neoliberal e Socialista, os últimos, como Caio Prado Junior, Nelson Werneck Sodré e Alberto Passos Guimarães e, em uma posição independente, Inácio Rangel.

Ainda com relação ao segundo capítulo, defende o autor que o Pensamento Neoliberal tinha como expoentes no Brasil Roberto Simonsen, Roberto Campos e João Paulo de Almeida Magalhães. A corrente por eles representada conseguiu lograr êxito com sua teoria e a aplicação de seus modelos também na Argentina terminou em projetos de privatizações em ambos os países.

O terceiro capítulo é onde temas "atuais" do desenvolvimento (local, regional e territorial) são apresentados. Segundo o autor, os elementos comuns aos três conceitos são:(i) referem-se a um processo de mudança estrutural localizado; (ii) remetem a uma responsabilidade fundamental da sociedade regional; (iii) incluem a dinamização socioeconômica associada à melhoria da qualidade de vida da população. Aqui é lugar de discussão e apresentação de conceitos como: a acumulação flexível ou especialização flexível, a Escola da Regulação de origem Francesa, os Distritos Industriais Italianos, a Economia Evolucionária, Meio Inovador, Sistemas de Inovação, Regiões Inteligentes, Classe Criativa e Regiões Engenhosas, Institucionalismo e Neoinstitucionalismo, Nova Economia Institucional e Capital Social.

O autor se preocupa nessa parte do livro em resgatar abordagens de vanguarda sobre o impacto do desenvolvimento de países, territórios, regiões e lugares, apresentando importantes enfoques sistêmicos sobre desenvolvimento territorializado e a relação sociedade, 
economia e meio ambiente, tais como: Ecomarxismo, Ecofeminismo, Decolonialidade, PósDesenvolvimento, Economia Circular e Sistemas Agroalimentares e Agroflorestais.

O autor aponta no quarto capítulo que a abordagem territorial ganhou destaque juntamente com a (re)valorização do rural, tentando superar o viés demasiadamente setorial, até então predominante no Brasil. Assim, abordam-se temas como patrimônio territorial, revalorização territorial, territorialidade, identidade territorial, ancoragem territorial, ativos e recursos territoriais, governança territorial como método para gestão do território, atores, poderes, relações, processos de decisão, coordenação de políticas, processos de governança territorial e desenvolvimento territorial.

A força que ganha o título territorial está relacionada também à crise do Estado. A perda crescente de seu poder de regulação da economia privada, que seria resultado de transformações socioeconômicas e do esgotamento do modelo fordista de produção, que paulatinamente vai dando lugar ao processo de reestruturação contemporâneo do capitalismo e uma acumulação flexível, baseada na descentralização das plantas fabris resultado de uma maior mobilidade no espaço.

Finalmente, o capítulo que encerra o livro tenta resgatar o "real sentido de desenvolvimento", optando em chamar o "desenvolvimento" pelo conceito de desenvolvimento territorial, compreendido como

[...] um processo de mudança estrutural empreendido por uma sociedade organizada territorialmente, sustentado na potencialização dos recursos e ativos (materiais e imateriais, genéricos e específicos) existentes no local, com vistas à dinamização socioeconômica e à melhoria da qualidade de vida de sua população"2.

As teorias do desenvolvimento e uma síntese integradora são apresentadas em quadros extremamente didáticos, apontando-se, ainda, seus limites. Destaca o autor, pensadores do tema como Amartya Sen e Cornelius Castoriadis que relacionam o desenvolvimento com um "estado de felicidade" da pessoa humana, contemplando a multidimensionalidade do desenvolvimento: social, econômica, cultural, política, espacial e histórica.

Em suas considerações finais Dallabrida resgata o pensamento de Celso Furtado que destaca que o desenvolvimento tem sido contemporaneamente interpretado em dois sentidos distintos. O primeiro diz respeito à evolução de um sistema social de produção, à medida que este, mediante a acumulação de riquezas e o progresso das técnicas, torna-se mais eficaz, ou seja, eleva a produtividade do conjunto de sua força de trabalho. E o segundo relaciona-se com o grau de satisfação das necessidades humanas. O último está de acordo com o pensamento de Dallabrida, em consonância com Sen e Castoriadis.

O autor conclui então que o desenvolvimento deve ser conceituado segundo a acepção atribuída ao desenvolvimento territorial, ancorando-se em um território historicamente construído, na dimensão escalar, outorgando-se, portanto, conteúdo espacial, prevendo a mudança contínua para melhoria da qualidade de vida, por meio da construção de pactos socioterritoriais.

\section{Resenha recebida em: 18/09/2017}

\section{Resenha aprovada em: 19/09/2017}

\footnotetext{
${ }^{2}$ Conforme: DALLABRIDA, V. R. Governança territorial: do debate teórico à avaliação da sua prática. Análise Social, v. L $\left(2^{\circ}\right)$, n. 215,2015 , p. 325.
} 